\title{
Argument Structure: English Verbs of Suiting
}

\author{
Corinne Cortés \\ Universitat de Barcelona
}

\begin{abstract}
Intermediate to advanced students of English grammar are often confronted with grammatical paradoxes for which traditional grammar can only offer a descriptive solution. One such paradox is illustrated by the so-called verbs of suiting. These verbs are apparently transitive in structure but do not follow the same patterns of data found with true transitive verbs. In light of the aforementioned paradox, this paper has two purposes. The first purpose, the more specific, is to show that there is a principled reason behind the paradox suggested by English verbs of suiting, namely that such verbs do not assign an external theta role. The second purpose, the more general, is to establish a set of diagnostics, for both students and teachers of English grammar, which can be used to determine whether or not a given verb assigns an external theta role.
\end{abstract}

\section{Introduction}

A descriptive generalization about transitive verbs is that in the active voice they have both a subject and an object. The examples below contain two English transitive verbs, write and eat, which demonstrate this descriptive generalization.
(1) a. Mary wrote the schedule
b. The children ate all the cake

Greenbaum and Quirk point out a class of verbs they call "verbs of suiting" (suit, fit, become), which on the surface appear to be transitive verbs because they have both an apparent object and subject (360). ${ }^{1}$ Consider the examples below:

(2) a. That dress fits Mary perfectly.

b. The job described suits John better than you think.

c. That red scarf becomes Mary. 
The pattern of data shown with the verbs of suiting corresponds to that of the transitive structures cited in (1). On the surface level of the syntax, verbs of suiting appear to have the same structure as transitive verbs. This structure can be illustrated as follows:

\section{(3) NP1 V NP2}

The purpose of this article is to show that, despite an apparent structural similarity with transitive verbs, English verbs of suiting are not transitive verbs at the underlying level of the syntax, and specifically, that verbs of suiting, unlike transitive verbs, do not assign an external theta role.

The article is structured as follows. In section 2 I discuss verbal argument structure. I follow proposals by Williams (23) and Grimshaw (1). Sections 3, 4 and 5 are dedicated to providing diagnostics for the presence of an external argument in structures containing verbs of suiting; section 3 addresses verbs of suiting and the passive structure, section 4 the causative/anticausative alternation described by Zubizarreta and section 5 nominalizations (262). Section 6 contains concluding remarks.

\section{Background Assumptions}

In this section I provide a general overview of argument structure along the lines of Williams (23). I then provide a more specific definition of the concept of external argument following proposals by Grimshaw (1).

Transitive and intransitive verbs are thought to assign an external theta role. The element to which the external theta role is assigned is most often realized as the subject of the clause. Transitive verbs subcategorize for minimally one internal argument, most often realized as the object of the clause. Assuming the VP internal subject hypothesis (Koopman and Sportiche, Subjects 12; Sportiche 21, among others) which generates the external argument VP-internally at the underlying level of the syntax, and Larson's (356) clausal structure in which verb phrases are composed of shells or layers to accommodate the number of arguments, a monotransitive structure will appear as follows at the underlying level of the syntax ${ }^{2}$ :

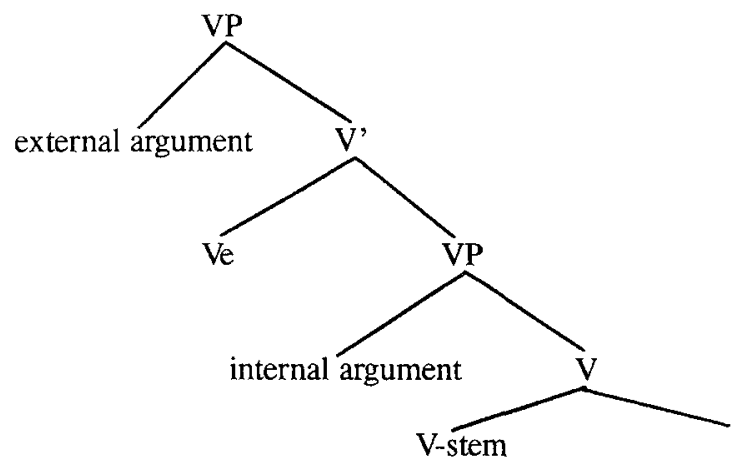


An intransitive verb phrase will be comprised of only the upper shell to accommodate the external argument, but will not contain the lower shell given that intransitive verbs do not subcategorize for an internal argument. Unaccusative verbs subcategorize for an internal argument, which may be realized as the surface subject. ${ }^{3}$ They do not assign an external theta role. Within the structural framework I assume, the underlying structure of an unaccusative verb parallels that of the intransitive verb except that the argument which appears in the specifier of VP is an internal, not an external, argument, as shown in the diagram below:

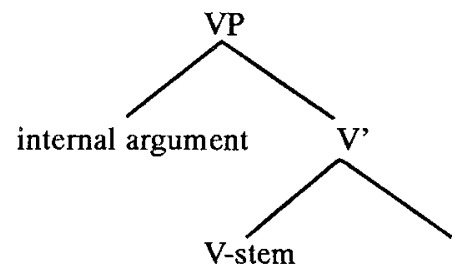

For the purposes of this paper, we will not be interested in a very technical definition of the term external argument. We will assume, following Grimshaw, that the external argument can be distinguished from all other arguments because it is maximally prominent both structurally and thematically (33). These concomitant conditions mean that the external argument must appear in the specifier of the highest VP at the underlying level of the syntax to achieve maximum structural prominence and also be the last element to be assigned a thematic role. Only if both criteria are met, can a given argument qualify as an external argument. In the next sections I propose three diagnostics to indicate the presence of an external argument and apply them to structures containing verbs of suiting.

\section{The Passive Structure}

The purpose of this section is to show that the ability to participate in the passive structure requires the presence of an external argument. I will compare the pattern of data with transitive verbs in the passive form to that of verbs of suiting in the passive form. First, however, I outline the analysis of the passive structure assumed herein.

Jaeggli shows that two properties are crucial to an analysis of the passive structure. He defines these properties as follows (591):

(l) absorption of the external theta role of the verb

(II) inability of the verb to assign accusative case

In regard to the first property, Jaeggli assumes with Chomsky (Remarks on Nominalizations 24) that theta roles and subcategorization features are "linked"; in short, theta roles are associated with a subcategorization feature (590). Thus, the external theta role of a verb, which is outside the domain of subcategorization, is not linked. The external 
theta role can therefore be "absorbed" by the passive morpheme (-en in English). Jaeggli also notes as a universal property of natural language that, in order to passivize, a verb must participate in assigning an external theta role (601). ${ }^{4}$ The second characteristic concerns case assignment. The underlying object as the surface subject receives nominative case, not accusative case. The next question then centers on the status of accusative case in the passive structure. Jaeggli concludes that structural accusative case is absorbed by the passive morpheme. To account for crosslinguistic variation he claims that case absorption may be parametrized with regard to the number of structural cases assigned by a verb and the types of verbs that assign structural case (610). For the purposes of this paper, however, the crucial property is assignment of an external theta role. The examples below contain transitive verbs in the active voice:

(6) a. John ate the apple you were saving

b. Peter cut the cake in thirds

Chomsky shows that if an agent-oriented adverb can be introduced into a structure, then an external theta role has been assigned. These structures allow agent-oriented adverbs, as the examples below show (Lectures on Government and Binding 103):

(7) a. John intentionally ate the apple you were saving

b. Peter purposely cut the cake in thirds

In the passive form of these structures, the underlying object, that is, the internal argument, becomes the surface subject, while the external argument is converted into an optional phrase:

(8) a. The apple you were saving was eaten by John

b. The cake was cut in thirds by Peter

We have further evidence that transitive verbs assign an external theta role. They not only allow passivization, but also allow an agent-oriented adverb in the passive structure, as shown by the examples below:

(9) a. The apple you were saving was intentionally eaten

b. The cake was purposely cut in thirds

Thus, we assume the hypothesis that transitive verbs assign an external theta role is correct. The next step is to apply these same tests to the verbs of suiting. The examples below contain verbs of suiting in the active voice:

(10) a. That job will suit Mary when she is older

b. The blue dress fit her perfectly last year

c. Short hair becomes him 
The next step is to determine whether or not the structures allow passivization. Consider the examples below:

(11) a. *Mary will be suited by that job when she is older

b. * She was fitted perfectly by that dress last year

c. ${ }^{*} \mathrm{He}$ is become by short hair

Passivization of the active form results in an ungrammatical structure. There is thus reason to suppose that the verbs of suiting do not assign an external theta role. For further evidence, an agent-oriented adverb can be inserted in the active form. Consider the examples below:

(12) a. ${ }^{*}$ That job will intentionally suit Mary when she is older

b. *The dress purposely fit her last year

c. * Short hair voluntarily becomes him

Not even in the active voice do verbs of suiting allow the insertion of an agent-oriented adverb, so there is further evidence for the claim that verbs of suiting do not assign an external theta role. In conclusion, the hypothesis that verbs of suiting do not assign an external theta role is supported by two forms of evidence. First, they cannot participate in passivization. ${ }^{5}$ Second, they do not admit an agent-oriented adverb. In the next section we will consider the pattern of data with verbs of suiting and Zubizarreta's causative/ anticausative alternation (262).

\section{Verbs of Suiting and the Causative/Anticausative Alternation}

In this section I examine another diagnostic for the presence of an external argument, the causative/anticausative alternation, which will show that verbs of suiting do not assign an external theta role. The strategy will be to compare the pattern of data found with the verbs of suiting to the pattern of data found with the frighen class of unaccusative psych-verbs, which, following Belletti and Rizzi, do not assign an external theta role (342). The first step is to summarize briefly the main points of Belletti and Rizzi's analysis of psych-verbs in section 4.1, and the second in section 4.2, to describe the diagnostic as it relates to psych-verbs and verbs of suiting (292).

Belletti and Rizzi discuss two classes of psych-verbs, the fear class and the frighten class (291). Grimshaw suggests that the argument structure for both classes is as shown below (41):
(13) $(x \quad(y))$
Exp Theme

Thus, the theme is the less thematically prominent of the two arguments. According to Grimshaw, the prominence relations are maintained configurationally, with the most 
prominent element in the argument structure acting as the subject of the verb in the fear class (42).

For the frighten class of verbs, however, the facts are not the same. Although the experiencer has maximal thematic prominence, it is not realized as the subject at the overt level of the syntax. Instead the theme is realized as subject. Belletti and Rizzi propose the following abstract representation for the frighten class of psych verbs (293) ${ }^{6}$ :

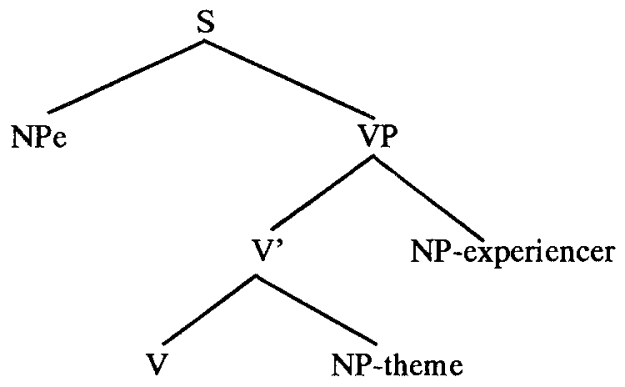

frighten

The subject position, specifier of $S$, is empty. Both the experiencer and the theme of the frighten class of psych-verbs are analyzed as internal arguments. Thus, the claim is that psych-verbs of the frighten class do not assign an external theta role.

Grimshaw, following Chomsky (Remarks on Nominalization 26), proposes that the critical difference between the two subclasses of psych-verbs is that the frighten class has a causative meaning not shared by the fear class (32). The idea is that the surface subject causes a change in the psychological state of the object, so verbs in the frighten class are causative not stative. According to Grimshaw, the structural argument is that the frighten class of psychological predicates has no external argument because the experiencer is thematically more prominent but not aspectually more prominent, while the causative argument is aspectually, but not thematically, more prominent. ${ }^{7}$ In the next section I apply Zubizarreta's causative/anticausative alternation diagnostic to the frighten class of pyschverbs (262).

Zubizarreta shows that certain verbs can participate in what she calls the causative/anticausative alternation (262). The examples below serve to illustrate this alternation.

(15) a. Someone broke the glass

b. The glass broke

Both the causative (a) and anticausative (b) examples are grammatical. Grimshaw suggests that such an alternation is possible only when an external argument is present (36). Given that the frighten class of psych-verbs does not assign an external theta role, it should not be able to participate in the causative/anticausative alternation. As the examples below show, the data bear out this hypothesis: 
(16) a. Someone frightened John

b. *John frightened

Verbs of the frighten class do not participate in the causative/anticausative alternation, so, following Grimshaw, this test shows that such verbs do not assign an external theta role. The next step is to apply this diagnostic to verbs of suiting (37). The examples below contain verbs of suiting in the causative/anticausative alternation:

(17) a. Someone suited John

b. *John suited

(18) a. Someone fit Mary

b. * Mary fitted

(19) a. Some clothes become Mary

b. *Mary becomes

These verbs show the same pattern of data as psych-verbs of the frighten class. They do not participate in the causative/anticausative alternation. This diagnostic, like the passive and agent-oriented adverb tests of the previous section, suggests that verbs of suiting do not assign an external theta role, and that, therefore, no external argument appears in their underlying structure. In the next section I examine a final diagnostic for the presence of an external theta role.

\section{Nominalizations}

In section 3 it is shown that the ability to participate in passivization involves suppression of an external theta role. Applying this analysis to verbs of suiting, we find that since they assign no external theta role, they cannot participate in the process. Similarly, the ability to undergo nominalizations is related to the suppression of an external theta role. If an external theta role is not present in a structure, nominalization will not be possible (compare Zubizarreta [275] and Grimshaw [87]). Zubizarreta examines structures such as the following (275):

(20) The enemy destroyed the city

She proposes an uncontroversial theta structure for this example, in which the external argument is assigned the thematic role of agent and the internal argument the thematic role of theme:

(21) [Agent $_{\text {The enemy] destroyed [Theme }}$ the city]

This structure can be nominalized as the example below shows. The external argument (agent) becomes a subjective genitive and the internal argument (theme) becomes the complement of the preposition of: 
(22) The enemy's destruction of the city

Following the lines of this analysis, because nominalization may form destruction from destroy, we assume that the verb destroy assigns an external theta role. The next step is to attempt to form a nominal from the psych verb frighten, which following Belletti and Rizzi, does not assign an external theta role (291). Consider the examples below:

(23) a. The movie frightened John

b. *The movie's fright(ening) of John

As expected, nominalization is not possible with the verb frighten due to the lack of external argument. The next step is to apply this diagnostic to the class of verbs of suiting. The pairs of examples below contain verbs of suiting with the (b) examples representing the ungrammatical nominalizations of the (a) examples:

(24) a. Those shoes suit that outfit

b. 'Those shoes' suit(ing) of that outfit

(25) a. That suit fits Paul

b. 'That suit's fit(ting) of Paul

(26) a. His short hair becomes him

b. *His short hair's becoming of him

In conclusion, verbs of suiting pattern with the frighten class of psych-verbs, which do not assign an external theta role, instead of with the destroy class of transitive verbs, which do assign an external theta role.

\section{Conclusion}

Despite apparent surface similarities with transitive verbs, it is clear that verbs of suiting are not transitive verbs. The hypothesis that verbs of suiting do not assign an external theta role, and thus, have no external argument in their argument structure, is supported by the patterns of data examined with agent-oriented adverbs, the passive structure, the causative/anticausative alternation and nominalizations. Verbs of suiting are therefore differentiated from true transitive verbs by means of a principled structural reason and the apparent paradox is accounted for. ${ }^{8}$ Furthermore, the diagnostics established herein can be applied by both students and teachers of English grammar to other classes of verbs to determine whether or not a an external theta role is assigned.

\section{Notes}

1. See 359-60, section 12.16. Included in this classification are verbs of measure (weigh, cost, etc.), reciprocal verbs (resemble, equal, etc.) and some verbs of containing (comprise, lack). In this paper I will only address the verbs of suiting. 
2. Chomsky (“A Minimalist Program” 16) assumes Larson's structure and proposes a series of functional projections (AGRPS, AGRPO, TP) above VP which I do not represent here because their presence or absence does not affect the analysis (356).

3. See Perlmutter (157) and Burzio (27) on the unaccusative hypothesis.

4. The property of being able to assign an external theta role is not the only requirement for passivization in English. For example, English intransitive verbs cannot passivize:

(I) a. John slept all night

b. *It was slept all night (by John)

In German, however, intransitives may passivize:

(II) es wurde getanzt/it was danced

In Arabic and Hebrew as well intransitives can be passivized. For discussion see Chomsky (Lectures on Government and Binding 125).

5. The fact that verb of suiting cannot passivize is also noted by Jackendoff (44) and Emonds (92).

6. In the updated framework of Chomsky these examples would have a more articulated structure ("A Minimalist Program"16). I will not go into details as these facts do not affect the central analysis.

7. It appears that the verb frighten allows passivization, so it would have an external argument according to the analysis in section 3 :

(I) John was frightened by the storm

This is an instance, however, of adjectival passivization. See Wasow (256).

8. The full argument structure of such verbs is not addressed here. One possibility is that such verbs take small clauses. See Stowell (285) and Chomsky ("A Minimalist Program" 8). A second is that they are unaccusative verbs with two internal arguments. Compare Belletti and Rizzi (291).

\section{Works Cited}

Belletti, Adriana, and Luigi Rizzi. "Psych-Verbs and Theta Theory." Natural Language and Linguistic Theory 6 (1988): 291-352.

Burzio, Luigi. Italian Syntax. Dordrecht: Reidel, 1986.

Chomsky, Noam. "A Minimalist Program for Linguistic Theory." The View from Building 20. Ed.

Kenneth Hale and Samuel J. Keyser. Cambridge: MIT P, 1993. 1-52. . Lectures on Government and Binding. Dordrecht: Foris, 1981.

"Remarks on Nominalization." Readings in English Transformational Grammar. Eds.

Ralph Jacobs and Paul S. Rosenbaum. Waltham: Ginn, 1970. 1-33.

Emonds, Joseph. A Transformational Approach to English Syntax. New York: Academic P, 1976. Greenbaum, Sidney, and Randolph Quirk. A University Grammar of English. London: Longman, 1973.

Grimshaw, Jane. Argument Structure. Cambridge: MIT P, 1990.

Jackendoff, Ray. Semantic Interpretation in Generative Grammar. Cambridge: MIT P, 1972. 
Jaeggli, Osvaldo. "Passive." Linguistic Inquiry 17 (1986): 587-622.

Koopman, Hilda, and Dominique Sportiche. "Subjects." Manuscript. Los Angeles: U of California, 1988.

.The Position of Subjects." Manuscript. Los Angeles: U of California, 1990.

Larson, Richard. "On the Double Object Construction." Linguistic Inquiry 19 (1988): 335-91.

Perlmutter, David. "Impersonal Passives and the Unaccusative Hypothesis." Berkeley Linguistic Society 4 (1978): 157-89.

Sportiche, Dominique. "Movement, Agreement and Case." Manuscript. Los Angeles: U of California, 1990.

Stowell, Tim. "Subjects Across Categories." The Linguistic Review 2 (1983): 285-312.

Wasow, Thomas. "Transformations and the Lexicon." Formal Syntax. Eds. Paul Culicover, Thomas Wasow, and Adrian Akmajian. New York: Academic P, 1977. 249-73.

Williams, Edwin. "Argument Structure and Morphology." The Linguistic Review 1 (1981): 1-34.

Zubizarreta, Maria Luisa. "The Lexical Encoding of Scope Relations among Arguments." Syntax and the Lexicon: Syntax and Semantics 24. Ed. Eric Wehrli and Tim Stowell. New York: Academic P, 1992. 251-79. 